\title{
INTERESTING CASES OF DIFFERENT TYPES OF CERVICAL FIBROIDS
}

Narmadha $^{1}$, Jamila Hameed ${ }^{2}$, Radhika $3{ }^{3}$, Geetha ${ }^{4}$, Jaisree ${ }^{5}$

\section{HOW TO CITE THIS ARTICLE:}

Narmadha, Jamila Hameed, Radhika, Geetha, Jaisree. "Interesting cases of different types of Cervical Fibroids". Journal of Evolution of Medical and Dental Sciences 2014; Vol. 3, Issue 18, May 05; Page: 4775-4780,

DOI: $10.14260 /$ jemds/2014/2510

ABSTRACT: The incidence of cervical fibroids is $0.5-1 \%$. It is usually single; they are usually confined to supravaginal portion of the cervix. Rarely it becomes submucous and polypoidal. So it is usually subserous or interstitial. It can be anterior, posterior or central in position. We had different types of cervical fibroids of which we will describe a few. Usually cervical fibroids cause infertility, difficulty in labor, infections, metrorrhagia, menorrhagia, constipation, retention of urine and dyspareunia. The cervical fibroid distorts the shape of cervix and grows bigger. It pushes the uterus upward giving the appearance of lantern of Saint Paul's dome in a case of a central cervical fibroid. Most of the patients in the reproductive age get admitted for menorrhagia due to fibroid. Its growth is dependent on estrogen. It does not grow after menopause.

KEYWORDS: Cervical fibroid, fibroid polyp, hysterectomy.

CASE 1: A 52 year old housewife, completed the family, who had previous two LSCS section and sterilization done 20 years ago, got admitted with retention of urine for the past 12 hours. She gave history of burning micturition and frequent retention of urine for which catheterization was done a number of times outside.

She had lower abdominal pain and post coital bleeding. She had irregular menstrual history. Foley's catheter was introduced. Bimanual examination showed cervix was replaced by huge mass $8 \times 11 \mathrm{~cm}$ occupying the whole cervix and vagina. This was a central cervical fibroid wherein the uterus was found sitting on top of it.

The uterus was palpable per abdomen as a soft globular mass $2 \times 3 \mathrm{~cm}$ suggestive of a fundal fibroid. Patient was anemic and 2 units of blood transfusion were given. Routine investigations were normal. Ultrasound(USG) report showed a small fundal fibroid $2 \times 2 \mathrm{~cm}$ and a huge central cervical fibroid of size $8.3 \times 11.3 \mathrm{~cm}$ (figure1). Patient was explained and consent for laparotomy was obtained.

Laparotomy showed plenty of adhesions due to previous surgeries which were released .The bladder was found plastered with the mass. So a transverse incision was made at the level of the UV fold to push the bladder up. Uterine vessels supplying the fibroid were engorged and tortuous were carefully cut and ligated (figure 2).

The uterus along with the central cervical fibroid shelled out without injuring the bladder, ureter and rectum. Pre-operative ureteric stenting could have helped in the surgery of shelling the cervical fibroid. Vault and abdomen closed after perfect hemostasis. The cut section of the specimen showed the uterus sitting on top of the cervical fibroid and had a small fundal fibroid of size $3 \times 3 \mathrm{~cm}$.

The specimen was sent for histopathology, because of the increased cellularity and mitosis, leiomyosarcoma was thought of initially by the pathologist. Later on, they confirmed it as a feature of highly cellular leiomyoma with hyaline and cystic degeneration (figure 2) Post-operative period was uneventful. Patient passed urine freely. She came for follow up. She had no complaints. 


\section{CASE REPORT}

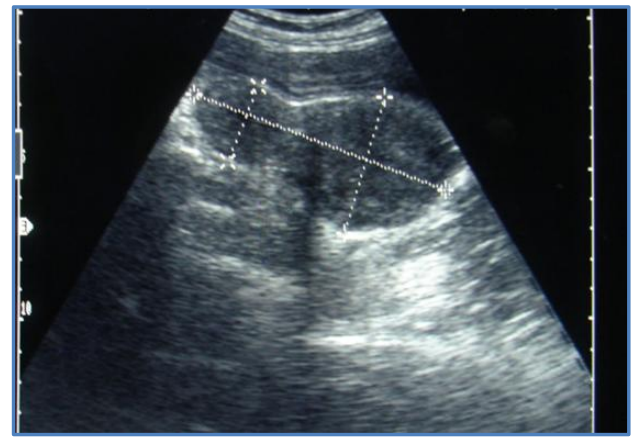

Figure 1: USG

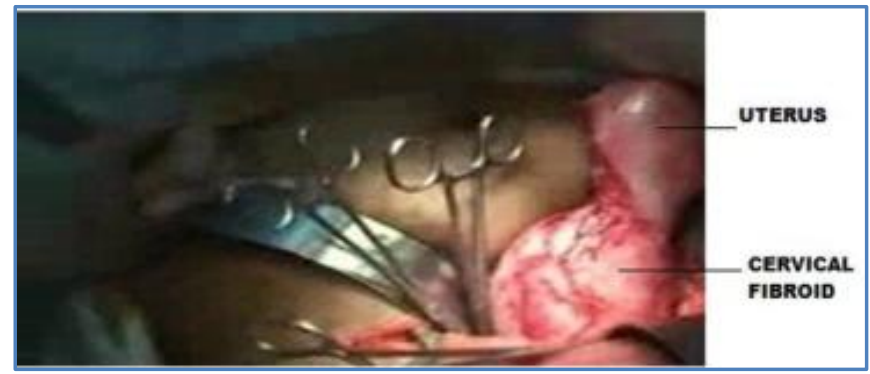

Figure 2

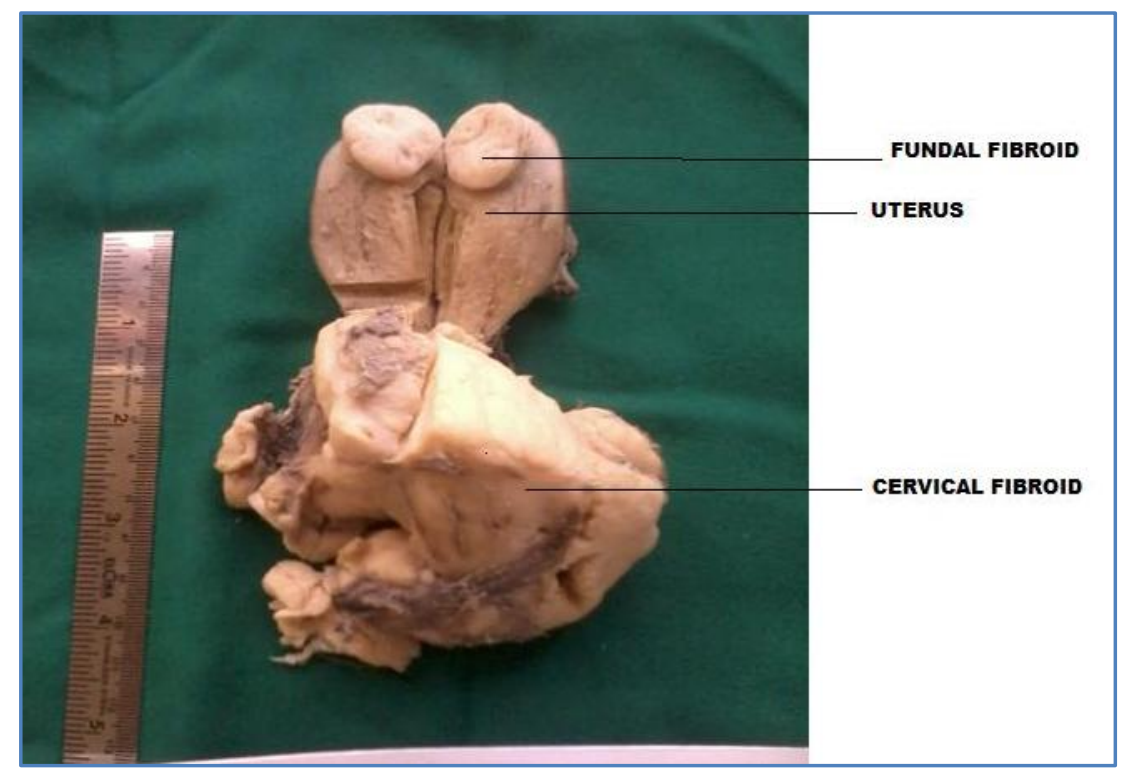

Figure 3

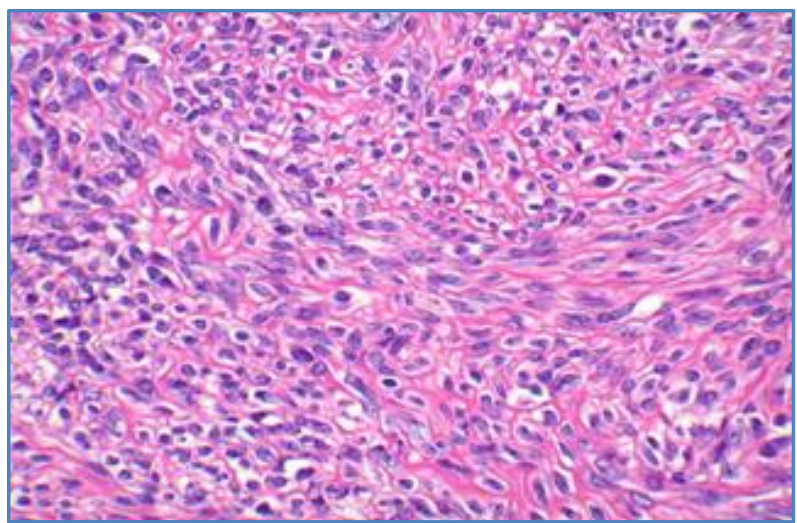

Figure 4: leiomyoma with hyaline degeneration 


\section{CASE REPORT}

CASE2: A 45 year old lady came with profuse, irregular intermenstrual and postcoital bleeding for the past 2 years. On examination she was anemic. Per abdomen uterus was not palpable. She had a scar due to sterilization done 20 years ago. Vaginal examination could not be done as there was a huge mass occupying the whole vagina.

We could not feel the cervix. Routine investigations were done, everything was normal but hemoglobin was $5.1 \mathrm{gm} \%$. Ultrasound showed large hypoechoic myoma of size $8.5 \times 7.8 \mathrm{cms}$ in the cervical region occupying the whole vagina as a cervical fibroid. Urine culture showed pseudomonas growth and was treated with amikacin. Patient was given 3 units of blood.

Patient was taken up for laparotomy by pfannensteil incision. As usual after clamping, cutting and ligating the uterine arteries, the uterus was bisected (figure 5) upto the supravaginal portion of the cervix, after securing perfect hemostasis by ligating the vessels supplying the mass, the fibroid polyp was removed en mass. The cut section showed a typical fibroid (figure 6). The uterus also had multiple fibroids. She had a catheter for the bladder. Post-operative period was uneventful and she was discharged. She could pass urine freely. Histopathology revealed a leiomyoma (figure 7).

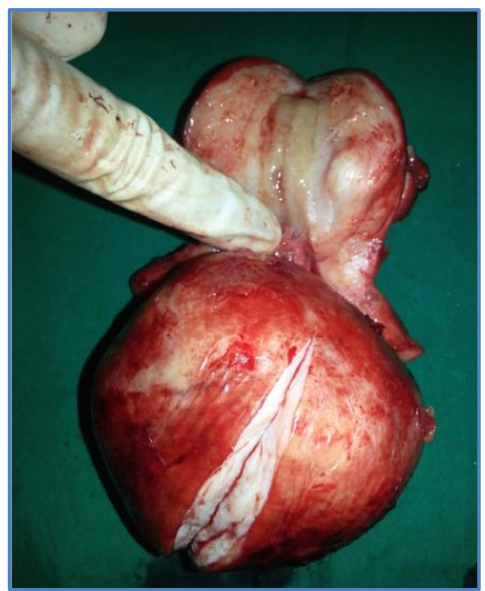

Figure 5

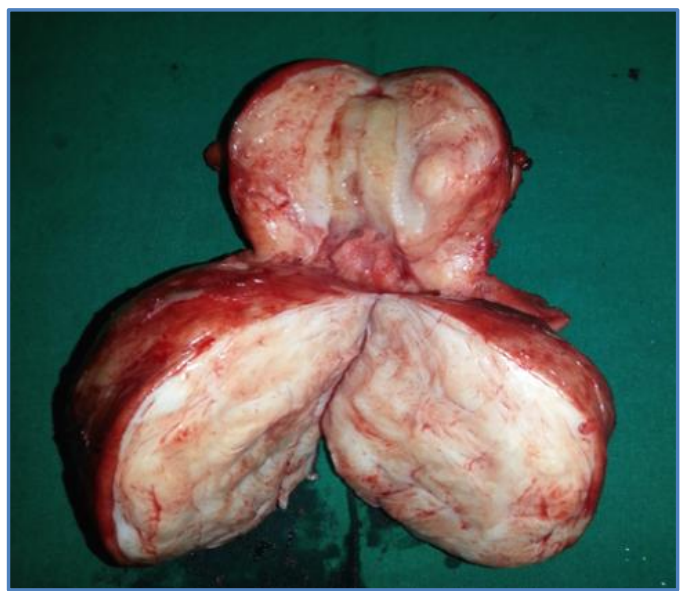

Figure 6

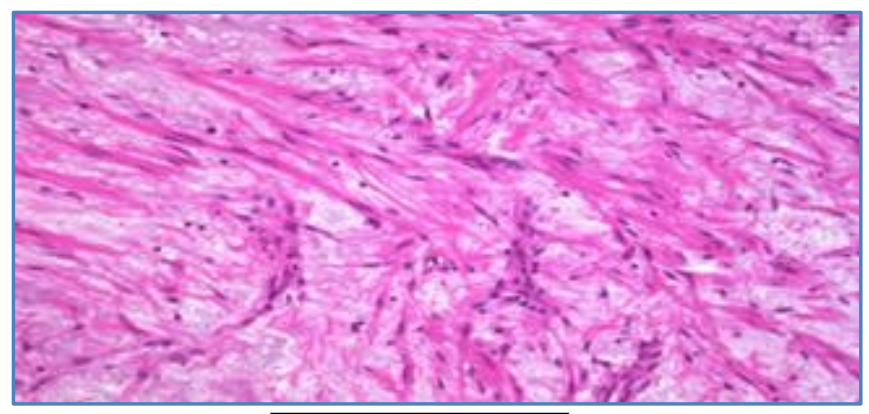

Figure 7

CASE 3: A 35 year old lady P2L2A2 had pain and swelling in the lower abdomen. Her menstrual cycles were regular. Per abdomen amass of 16 weeks size was palpable. The cervix was pushed up and hitched onto the pubic symphysis. The mobility of the uterus was restricted. The movement of 


\section{CASE REPORT}

the cervix was transmitted to the mass. All fornices fullness was present because of the mass. All investigations were normal. Ultrasound showed a normal size uterus and a posterior cervical fibroid size $13 \times 11 \mathrm{~cm}$. IVP showed hydroureter and hydronephrosis on the left side (Figure 8).

Bilateral DJ stenting (BDJS) was done prior to surgery. A small uterus was found and the cervical fibroid of size $13 \times 13 \mathrm{~cm}$ was found arising from the posterior side (Figure 9 ).

In this case laparotomy was done, as usual after clamping, ligating the uterine vessels, posteriorly a vertical incision was made to enucleate the cervical fibroid, without injury to the ureter thanks to BDJS. Cut section showed the cervical fibroid was arising from the posterior side (figure 10). The specimen was sent for histopathology, confirmed cervical leiomyoma.

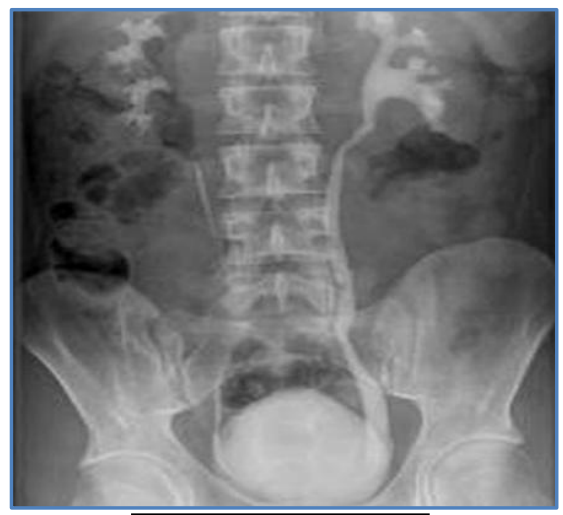

Figure 8

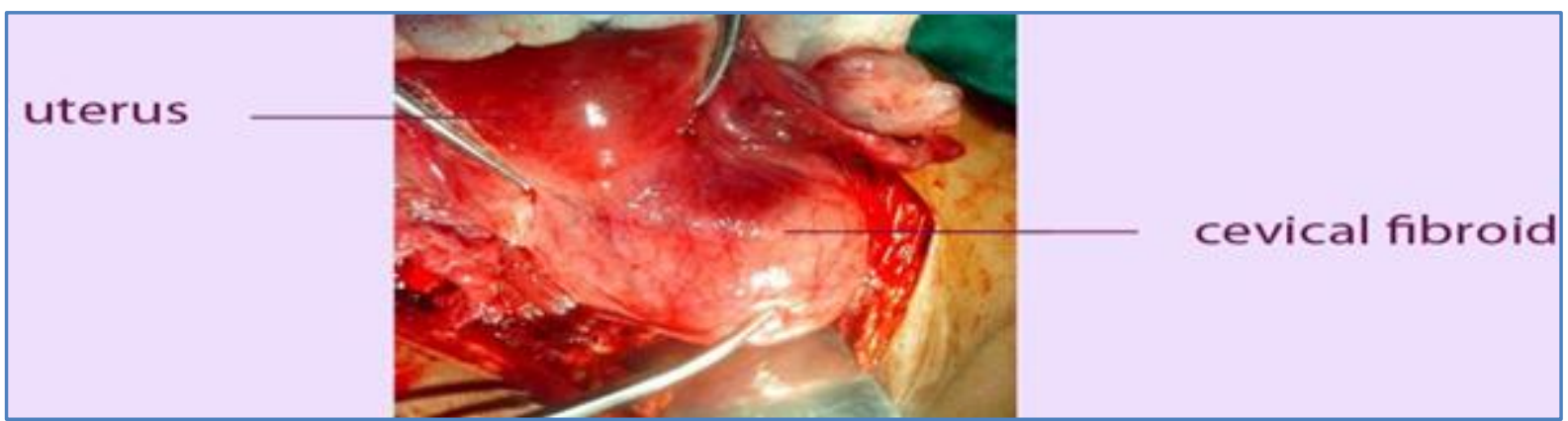

Figure 9

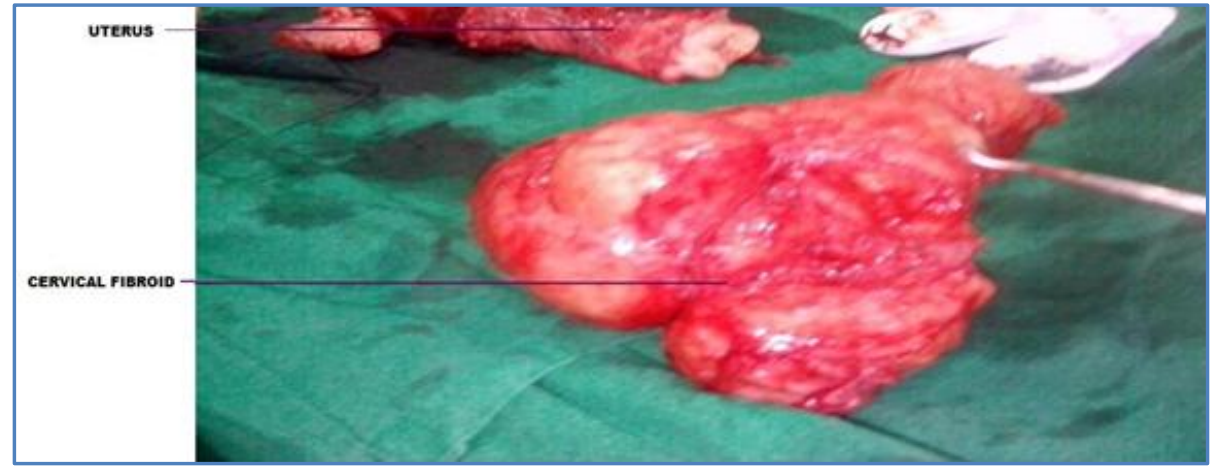

Figure 10 


\section{CASE REPORT}

DISCUSSION: Leiomyomas are the commonest benign swellings. The cervical fibroids incidence is $0.5-1 \%$. Sometimes present as a cervical myomatous polyp also. These develop from the wall of the cervix. ${ }^{1}$ Large fibroids are difficult to operate because of the close proximity to the vital organs like ureter, bladder needs experienced surgeons. ${ }^{2}$ The treatment of cervical fibroid is hysterectomy or myomectomy. Myomectomy can be performed through abdominal route, if there is a good pedicle present, can be performed vaginally. Sometimes, a huge cervical fibroid may enlarge to occupy the abdomen and present as a mass. ${ }^{3}$

In younger patients if the cervical myoma has got a pedicle, can be removed easily by blunt dissection performed by vaginal route with low morbidity. ${ }^{4}$ Nowadays laparoscopic myomectomy and hysterectomy are performed. ${ }^{5}$ A vaginal myoma can be mistaken for a cervical myoma. ${ }^{6}$ Sometimes a cervical fibroid can mimic chronic inversion. ${ }^{7}$ Acute retention of urine is one of the complications in a cervical fibroid, which is managed with cystoscopy and transurethral endoscopic resection. ${ }^{8}$ Just as in the case of fibroid uterus the histopathology shows myxoid degeneration, the same thing can be noted in the cervical leiomyoma. ${ }^{9}$

\section{REFERENCES:}

1. Tiltman AJ. Leiomyomas of the uterine cervix: a study of frequency. Int J Gynecol Pathol. 1998 Jul; 17(3):231-4.

2. Kshirsagar SN, MM Laddad. Unusual Presentation of Cervical Fibroid: Two Case Reports. International Journal of Gynae Plastic Surgery, 2011; 3 (1):38-39.

3. Basnet $\mathrm{N}$ et al. An unusual presentation of huge cervical fibroid. Kathmandu Univ Med J (KUMJ). 2005 Apr-Jun; 3 (2):173-4.

4. Renu G. Two uncommon presentations of cervical fibroids. People's journal of scientific research. July 2012 Vol. 5(2), 36-8

5. Patel P et al. Handling cervical myomas. J Gynecol Endosc Surg. 2011 Jan; 2 (1):30-2.

6. Chakrabarti I, De A, Pati S. Vaginal leiomyoma. J Midlife Health. 2011 Jan; 2 (1):42-3.

7. Swati S, Priyakshi C. Central cervical fibroid mimicking as chronic uterine inversion: a case report. Int J Reprod Contracept Obstet Gynecol. 2013; 2(4): 687-68

8. Agrawal SK et al. Bladder neck leiomyoma presenting with acute retention of urine in an elderly female. J Midlife Health. 2014 Jan; 5(1):45-8.

9. Kamra H Tet al. Myxoid leiomyoma of cervix. J Clin Diagn Res. 2013 Dec; 7(12):2956-7. 


\section{AUTHORS:}

1. Narmadha

2. Jamila Hameed

3. Radhika

4. Geetha

5. Jaisree

\section{PARTICULARS OF CONTRIBUTORS:}

1. Tutor, Department of Obstetrics and Gynaecology, Vinayaka Mission's Medical College \& Hospitals, Karaikal.

2. Professor, Department of Obstetrics and Gynaecology, Vinayaka Mission's Medical College \& Hospitals, Karaikal.

3. Professor, Department of Obstetrics and Gynaecology, Vinayaka Mission's Medical College \& Hospitals, Karaikal.

4. Assistant Professor, Department of Obstetrics and Gynaecology, Vinayaka Mission's Medical College \& Hospitals, Karaikal.
5. Post Graduate, Department of Obstetrics and Gynaecology, Vinayaka Mission's Medical College \& Hospitals, Karaikal.

\section{NAME ADDRESS EMAIL ID OF THE CORRESPONDING AUTHOR:}

Dr. Jamila Hameed,

Professor,

Department of Obstetrics and Gynecology,

Vinayaka Mission's Medical and Hospital,

Karaikal-609609.

E-mail: jamilahameed@gmail.com

Date of Submission: 02/04/2014. Date of Peer Review: 03/04/2014. Date of Acceptance: 08/04/2014.

Date of Publishing: 29/04/2014. 